This item was submitted to Loughborough's Research Repository by the author.

Items in Figshare are protected by copyright, with all rights reserved, unless otherwise indicated.

\title{
Comments on 'Combined effect of variable viscosity and thermal conductivity on free convection flow of a viscous fluid in a vertical channel using DTM' by J.C. Umavathi and M. Shekar
}

\section{PLEASE CITE THE PUBLISHED VERSION}

http://dx.doi.org/10.1007/s11012-016-0497-9

\section{PUBLISHER}

(C) Springer

\section{VERSION}

AM (Accepted Manuscript)

\section{PUBLISHER STATEMENT}

This work is made available according to the conditions of the Creative Commons Attribution-NonCommercialNoDerivatives 4.0 International (CC BY-NC-ND 4.0) licence. Full details of this licence are available at: https://creativecommons.org/licenses/by-nc-nd/4.0/

\section{LICENCE}

CC BY-NC-ND 4.0

\section{REPOSITORY RECORD}

Kay, Anthony. 2019. "Comments on 'combined Effect of Variable Viscosity and Thermal Conductivity on Free Convection Flow of a Viscous Fluid in a Vertical Channel Using DTM' by J.C. Umavathi and M. Shekar". figshare. https://hdl.handle.net/2134/21756. 


\section{Comments on "Combined effect of variable viscosity and thermal conductivity on free convection flow of a viscous fluid in a vertical channel using DTM" by J.C. Umavathi and M. Shekar}

\section{Anthony Kay}

Received: date / Accepted: date

Keywords Thermal convection - Viscous dissipation - Variable viscosity . Variable thermal conductivity

A recent paper by Umavathi and Shekar [1] addressed an important problem in thermal convection, but is unfortunately marred by several inadequacies.

Most seriously, the authors' assertion that the flow is free convection, i.e. driven solely by buoyancy forces, is incorrect. Their vertical momentum equation is

$$
\frac{\mathrm{d}}{\mathrm{d} Y}\left(\mu \frac{\mathrm{d} U}{\mathrm{~d} Y}\right)+\rho_{0} g \beta\left(T-T_{0}\right)=0
$$

which is apparently obtained by subtracting the hydrostatic equation from the vertical component of the Navier-Stokes equation. However, the reference temperature $T_{0}$ is arbitrary; it is simply the temperature at which the density, viscosity and thermal conductivity take their respective reference values $\rho_{0}$, $\mu_{0}$ and $K_{0}$. If we integrate (1) across the channel, we find that the total skin friction at the channel walls takes an arbitrary value, depending on the choice of $T_{0}$. This absurd result indicates that the choice of reference temperature in the momentum equation cannot be arbitrary. Indeed, as long ago as 1999 it was shown by Barletta and Zanchini [2] that for convection in vertical channels it is essential to take the cross-section mean temperature as the reference temperature; the reason for this was subsequently explained by Schneider [3] and in some detail by Kay [4]. Only with this choice of reference temperature does the momentum equation have the correct force balance, in which the total skin friction is balanced by the dynamic pressure gradient (i.e. total

Anthony Kay

Department of Mathematical Sciences, Loughborough University, Loughborough, Leicestershire, LE11 3TU, United Kingdom

Tel.: +44-1509-222878

E-mail: A.Kay@lboro.ac.uk 
minus hydrostatic pressure gradient). The velocity profiles plotted in all the various cases examined by the authors show that the total skin friction is in general not zero; hence there must be a dynamic pressure gradient, so the convection is partly forced, not free. This is particularly obvious when one considers the velocity profiles plotted with $m=0$, where there is upward Poiseuille flow with no temperature difference between the walls. Any attempt to interpret the plotted results physically, in particular to understand why velocity and temperature profiles differ as parameters such as $b_{v}$ and $b_{k}$ are varied, is thus hampered by the unacknowledged differences in applied pressure gradient between different cases.

In this connection, we should also note errors in the definition of skin friction in [1]. Firstly, when considering variable viscosity, the viscosity factor must be included in the skin friction. Secondly, there is a sign error: if skin friction is to be defined consistently, as shear stress exerted by the fluid on the wall (which is important for the force balance discussed above), then there should be a minus sign at $y=1$. Thus the dimensionless skin friction at $y=1$ should be

$$
\tau_{2}=-\left.\frac{\mu}{\mu_{0}} \frac{\mathrm{d} u}{\mathrm{~d} y}\right|_{y=1} .
$$

Similar comments apply to the definition of Nusselt number, which is the dimensionless heat flux at the walls: a factor of $K / K_{0}$ should be included, and for consistency in defining $N u$ as heat flux out of the fluid, a minus sign should appear at $y=1$.

A quantity $\Delta T$ is used in the definition of many of the dimensionless variables and parameters in [1], but nowhere is $\Delta T$ defined. The temperature profiles reveal that in fact $\Delta T=T_{2}-T_{0}$, and so the the arbitrariness of $T_{0}$ also means that quantitative results cannot be extracted from the results for dimensionless parameters. A more suitable temperature scale to use might be $T_{2}-T_{1}$; this would preclude consideration of the case where the wall temperatures are equal, but that would not be an issue if one wanted to study true free convection.

Exponential formulae for the variations of viscosity and thermal conductivity with temperature are written down in [1] (without any justification in terms of the physics of any real fluid), but then linear approximations are used in all subsequent calculations. Indeed, equation (14) in [1] claims the linear formula to be equal (not merely approximately equal) to the exponential formula! It is not clear why the exponential formulae were written down at all; equations consistent to first order in $b_{v}$ and $b_{k}$ with the dimensionless governing equations (8), (9), (15), (16), (19), (20) in [1] could have been obtained by starting with linear formulae for $\mu(T)$ and $K(T)$.

The so-called Differential Transform Method is nothing more than the method of expansion in power series, recast to look analogous to an integral transform. As such, it is well established as a method for solving linear ordinary differential equations, but has also been used for nonlinear equations, including those for thermal convection with viscous dissipation [4-7]. The advantages of the method are well described in [1], but care does need to be taken 
to ensure that the power series is convergent. This can be done by means of a Domb-Sykes plot or, as is successfully done in [1], by comparison with a numerical solution.

\section{References}

1. Umavathi JC, Shekar M (2016) Combined effect of variable viscosity and thermal conductivity on free convection flow of a viscous fluid in a vertical channel using DTM. Meccanica 51:71-86

2. Barletta A, Zanchini E (1999) On the choice of reference temperature for fully-developed mixed convection in a vertical channel. Int J Heat Mass Transfer 42:3169-3181

3. Schneider W (2011) Comments on M. Miklavčič and C.Y. Wang, Completely passive natural convection, ZAMM 91/7, 601-606 (2011). Z Angew Math Mech 91:1002-1004

4. Kay A (2016) When is natural convection completely passive? Z Angew Math Mech 96:279-303

5. Barletta A, Lazzari S, Magyari E (2007) Uni- and bidirectional mixed convection flow regimes described by dual solutions in a vertical duct. Acta Mechanica 194:83-102

6. Barletta A, Lazzari S, Magyari E (2008) Buoyant Poiseuille-Couette flow with viscous dissipation in a vertical channel. Z Angew Math Phys 59:1039-1056.

7. Miklavčič M, Wang CY (2011) Completely passive natural convection. Z Angew Math Mech 91:601-606 